\title{
Long non-coding RNAs: crucial regulators of gastrointestinal cancer cell proliferation
}

\author{
Jiaxin Chen ${ }^{1}$, Shuiping $\mathrm{Liu}^{1}$ and Xiaotong $\mathrm{Hu}^{1}$
}

\begin{abstract}
Studies of long non-coding RNAs (IncRNAs) have been prevalent in the field of non-coding RNA regulation in recent years. LncRNAs exert crucial effects on malignant cell processes in the gastrointestinal system, including proliferation. Aberrant IncRNA expression, through both oncogenes and tumor suppressor genes, is instrumental to tumor cell proliferation. Here, we summarize the different molecular mechanisms and relevant signaling pathways through which multifarious IncRNAs regulate cell proliferation and we show that IncRNAs are potential biomarkers for gastrointestinal cancers.
\end{abstract}

\section{Facts}

- Proliferation of gastrointestinal cancers is a consequence of dysregulated signaling pathways and ectopic cellular processes, such as the cell cycle, apoptosis, and angiogenesis.

- LncRNAs play either pro-proliferative or antiproliferative roles in human gastrointestinal cancers.

- LncRNAs regulate proliferation through interactions with RNA targets, localization to chromatin, or binding to proteins.

- Proliferation-related lncRNAs act on key molecules to activate or inhibit specific signaling cascades.

\section{Open questions}

- What cellular processes, e.g., the cell cycle, apoptosis, and angiogenesis, are influenced by lncRNAs to trigger malignant cell proliferation?

- Can lncRNAs from the same gene locus, e.g., 8q24, have similar functions or molecular targets?

- Can lncRNAs be used as biomarkers for gastrointestinal cancer diagnosis or prognosis?

\footnotetext{
Correspondence: Xiaotong Hu (hxt_hz@zju.edu.cn)

${ }^{1}$ Biomedical Research Center and Key Laboratory of Biotherapy of Zhejiang Province, Sir Run Run Shaw Hospital, Zhejiang University, Hangzhou, China These authors contributed equally: Jiaxin Chen, Shuiping Liu.

Edited by A. Rufini
}

How can we use them to decrease cancer proliferation?

\section{Introduction}

A set of transcripts termed long non-coding RNAs (lncRNAs) are some of the most commonly researched non-coding RNA networks. Because of increasingly indepth studies, it is likely that $\sim 70-80 \%$ of human genome can be transcribed into RNAs, and only $\sim 2-3 \%$ of these RNAs encode proteins ${ }^{1}$. The vast majority of transcripts are actually non-coding RNAs ${ }^{2}$. The arbitrary limits of a length of 200 nucleotides and the absence of any detectable open reading frame (ORF) distinguish lncRNAs from other non-coding RNAs ${ }^{3}$.

Gastrointestinal cancers have high morbidity and mortality rates, which has made them a serious public health problem. They are usually diagnosed in the advanced stages of the disease and there are only limited treatment strategies available. Colorectal cancer (CRC) is the third most common cancer in the world, with $\sim 1.4$ million newly diagnosed cases in 2012. Liver cancer is the second leading cause of cancer-related deaths worldwide in men, with an estimated 745,500 deaths. Although less frequent, other gastrointestinal cancers accounted for $\sim 723,100$ deaths from gastric cancer (GC) and 400,200 deaths from esophageal cancer (EC) in $2012^{4,5}$. 
Tumor cell proliferation is caused by dysregulated cell processes, such as cell cycle progression, apoptosis, and angiogenesis. Normal eukaryotic cells with healthy cell cycles have the ability to control the production and release of growth-promoting signals ${ }^{6}$. The positive control cyclin/cyclin-dependent kinase (CDK) complexes comprise different protein kinases and contribute to the initiation and progression of the cell cycle. CDK inhibitors (CDKIs), such as the ink4 (p15, p16, p18, and p19) and Cip/Kip (p21, p27, and p57) families of proteins, play opposite roles $^{7-9}$. Ectopic regulation of either the cyclins/ CDKs/CDKIs may impinge on cell proliferation and cause malignancy. LncRNAs play highly diverse roles in the regulation of many malignant cell processes, including proliferation ${ }^{10,11}$. This review summarizes the research progress with respect to the function of lncRNAs in the proliferation of gastrointestinal cancers, highlighting the molecular mechanisms and the recurring signaling pathways involved in these processes.

\section{Molecular mechanisms of IncRNAs in proliferation}

The function of lncRNAs in the regulation of tumor proliferation is doubled faced. On the one hand, some lncRNAs act as oncogene, promoting cell proliferation and survival, whereas, on the other hand, examples exists of lncRNAs that inhibits tumor cell growth. Consequently, IncRNAs are divided into pro-proliferative lncRNAs (Table S1) and anti-proliferative lncRNAs (Table S2). Additionally, some lncRNAs have reversed roles in different gastrointestinal cancers or adverse expression in the same cancer (Table S3). Despite their different functions, IncRNAs have common molecular mechanisms for modulating cell proliferation (Fig. 1).

The interaction between lncRNAs and other RNA targets is of great importance. The competing endogenous RNA (ceRNA)-crosstalk network has become a favorite of researchers over the past few years. CeRNAs are RNA transcripts that have special microRNA-binding sites called miRNA response elements (MREs) ${ }^{12}$. Many lncRNAs and mRNAs have MREs, which give them the ability to compete for shared miRNAs. In this case, IncRNAs and mRNAs can regulate each other's expres$\operatorname{sion}^{13-16}$. In many gastrointestinal malignancies, lncRNAs may function as ceRNAs to sponge miRNAs, which liberate targeted proliferation-relevant mRNAs at the posttranscriptional level ${ }^{17}$. LncRNAs also engage in RNA metabolism, such as mRNA splicing, transport, translation, and degradation. When localized to nuclear speckles, where abundant spliceosomal proteins and regulatory factors accumulate, IncRNAs coordinate the alternative splicing of pre-mRNA ${ }^{18}$. For instance, SF2/ASF (now called SRSF1) is one of the pivotal factors co-localized with metastasis and associated with lung adenocarcinoma transcript 1 (MALAT1) in nuclear speckles. MALAT1 recruits and changes the specific distribution of SF2/ASF to promote $\mathrm{GC}$ proliferation ${ }^{19}$. Complementarily, by direct binding or specific protein induction, cytoplasmic lncRNAs participate in the modulation of either mRNA stability or translation as promoters or inhibitors ${ }^{20}$. In addition, the hybrid duplex between lncRNAs-AS, such as KRT7-AS, and sense mRNAs of their cognate coding genes, have recently been identified in gastrointestinal cancer growth $^{21}$.

Some lncRNAs perform their functions when localized to chromatin ${ }^{22}$. Histone modification plays a central role in epigenetic transcriptional regulation. The acetylation of histones stimulates gene expression, while methylation has dual functions. Transcriptional activation is related to methylation at lysine 4,36 , and 79 of histone 3 (H3K4, H3K36, and H3K79), while silencing is associated with $\mathrm{H} 3 \mathrm{~K} 9$ and $\mathrm{H} 3 \mathrm{~K}_{27} 7^{23}$. Mounting evidence indicates that numerous lncRNAs localized in the nucleus regulate cell cycle progression and proliferation by recruiting chromatin remodeling complexes and specifying histone modification patterns on target genes for their positive or negative expression. The most common remodeling complexes, e.g., methyltransferase polycomb repressive complex 2 (PRC2) and demethylase lysine-specific demethylase1 (LSD1), are regulated by lncRNAs and are responsible for silencing the expression of growth-related genes $^{24,25}$. Nonetheless, several studies have demonstrated that upregulated zeste homolog2 (EZH2), known as a key component of PRC2, increases cyclin D1 expression and stimulates tumor cell growth, but the exact mechanism is unclear ${ }^{26,27}$. Gastric cancer-associated lncRNA 1 (GClnc1) is a molecular bridge that connects specific enzyme complexes, e.g., histone methyltransferase (WDR5) and acetyltransferase (KAT2A), with the target gene SOD2. SOD2 promotes proliferation because GClnc1 binds to and guides WDR5 and KAT2A to the SOD2 promoter, upregulating H3K4 trimethylation and H3K9 acetylation to improve its expression ${ }^{28}$.

In addition, lncRNAs actively interact with transcribed gene loci to control the expression of those genes. For instance, lncRNAs transcribed from some active chromatin states have a propensity for modulating the expression of their neighboring genes as enhancerassociated RNAs. By binding directly to the promoter sequences, these enhancer lncRNAs affect the transcription of proximal genes that are correlated tightly with cell proliferation and tumor growth in $\mathrm{cis}^{22}$.

Many studies have underscored the significance of crosstalk with diverse proteins. When lncRNAs interact with proteins, they function as scaffolds, guides, decoys, and signals ${ }^{29}$. LncRNA scaffolds with complicated and functional three-dimensional structures serve as a platform to collect regulatory protein partners, such as LSD1 and PRC2, to promoter regions of proliferation-related 


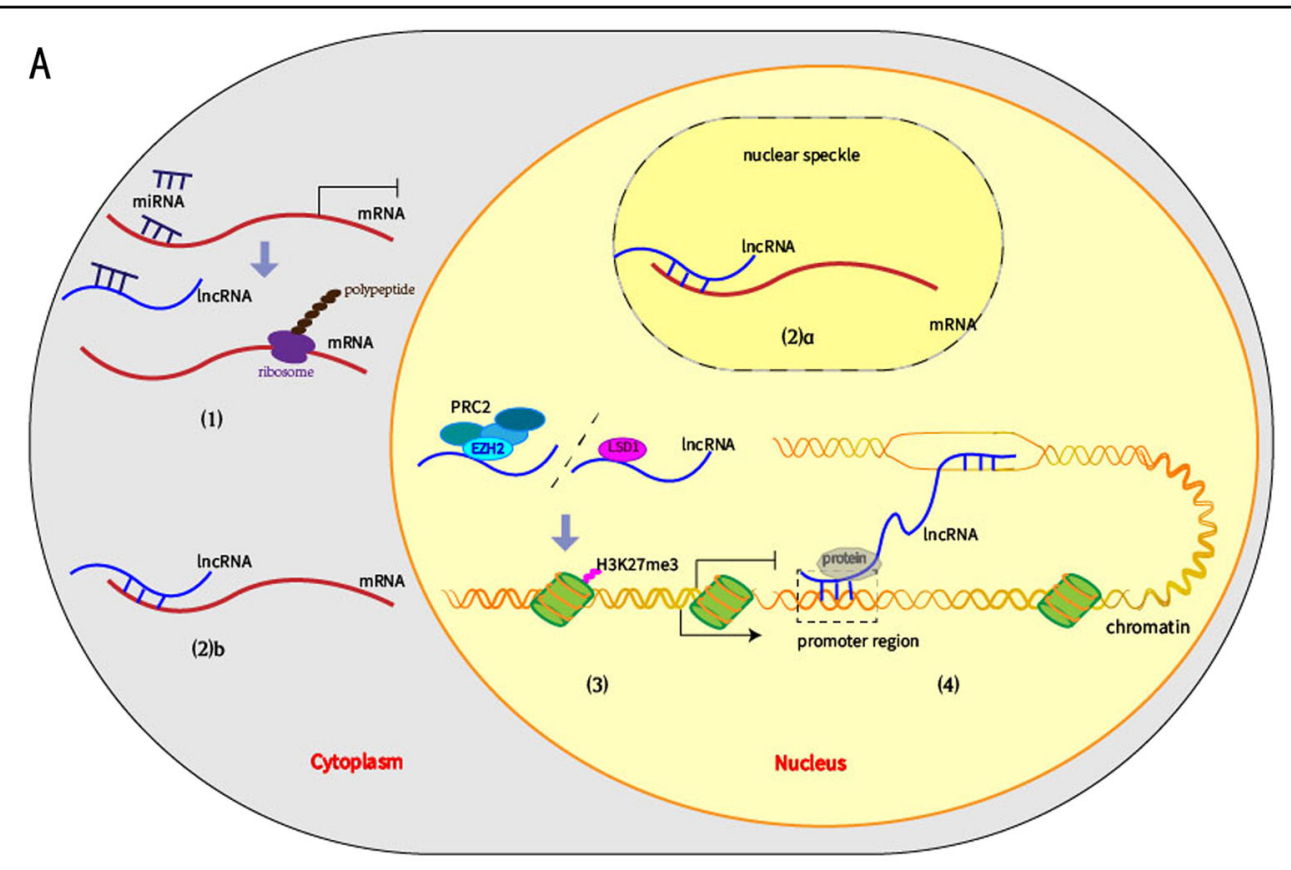

B

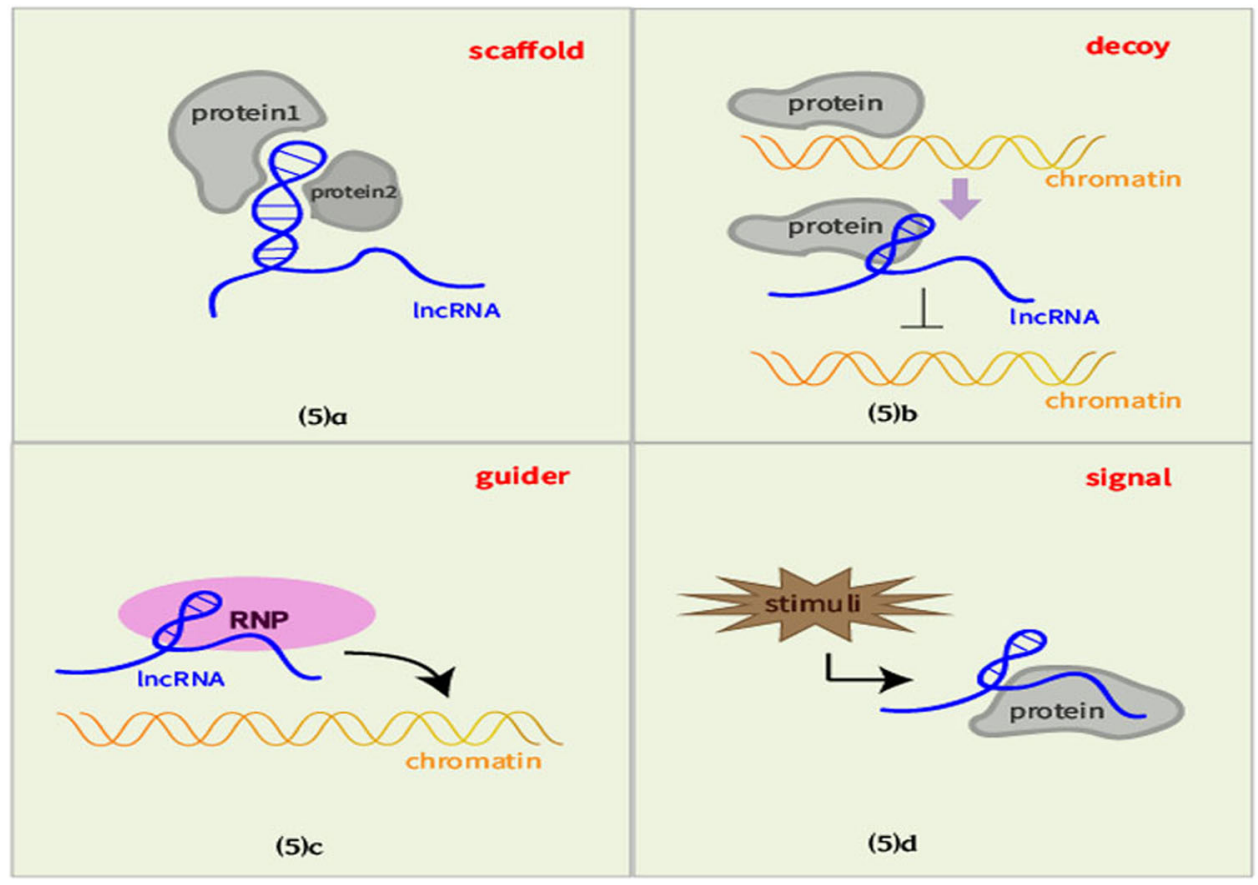

Fig. 1 LncRNAs share common molecular mechanisms that modulate proliferation. a(1) LncRNAs act as ceRNAs for mRNA targets related to proliferation. (2) LncRNAs participate in mRNA metabolism involving splicing (a), mRNA stability, translation, or degradation (b). (3) LncRNAs interact with chromatin remodeling complexes such as PRC2 or LSD1. (4) LnCRNAs bind to the promoter regions of neighboring genes as enhancers. $\mathbf{b}$ LncRNAs interact with proteins as (a) scaffolds to assemble multiple protein components into complexes; (b) decoys to keep proliferation-modulating proteins away from their targets; (c) guides that lead proteins such as RNPs to target sites; (d) signals with cell-type-specific expression to regulate proliferation

genes. Moreover, the formation of the complex including lncRNA and ribonucleoprotein (RNP), e.g., hnRNP-K, suggests that lncRNAs serve as guides that lead proteins to their target $\operatorname{sites}^{30}$. Some lncRNAs, such as the UHRF1 protein-associated transcript (UPAT), influence growth by modulating protein ubiquitination and degradation ${ }^{31}$. 
LncRNAs inhibit pro-ubiquitination proteins by acting as decoys that prevent them from executing their functions. Additionally, when confronted with various stimuli, some lncRNAs function as molecular signals, exhibiting celltype-specific expression and regulating biological events involving the cell cycle or apoptosis ${ }^{29}$.

\section{LncRNAs govern proliferation through different signaling pathways}

The malignant proliferation of gastrointestinal tumor cells is always accompanied by the dysregulation of multiple signaling pathways. LncRNAs mediate cell growth by acting on key molecules to activate or restrain specific signaling pathways.

\section{P53 signaling pathway}

As a canonical suppressor and crucial cell cycle gatekeeper, p53 is capable of suspending the cell cycle when eukaryotic cells suffer from drastic DNA damage or deficient oxygenation. Nonetheless, if the stress signals appear overwhelming and irreparable, p53 tends to induce permanent cell cycle arrest (cellular senescence) or apoptosis instead ${ }^{32}$. The p53 transcriptional response during carcinogenesis and tumor cell proliferation includes the activation and inhibition of various genes. The repressive function of p53 is closely correlated to that of $\operatorname{lncRNAs}{ }^{33}$. LncRNAs regulate p53 and are key components of the p53 pathway (Fig. 2) ${ }^{34}$.

p53 effectors are those lncRNAs coordinated by p53. There is a reciprocal repression feedback loop between loc285194 (LSAMP antisense RNA 3 or TUSC7) and microRNAs that belong to the ceRNA crosstalk networks, and loc285194 has a consensus response element (p53RE)

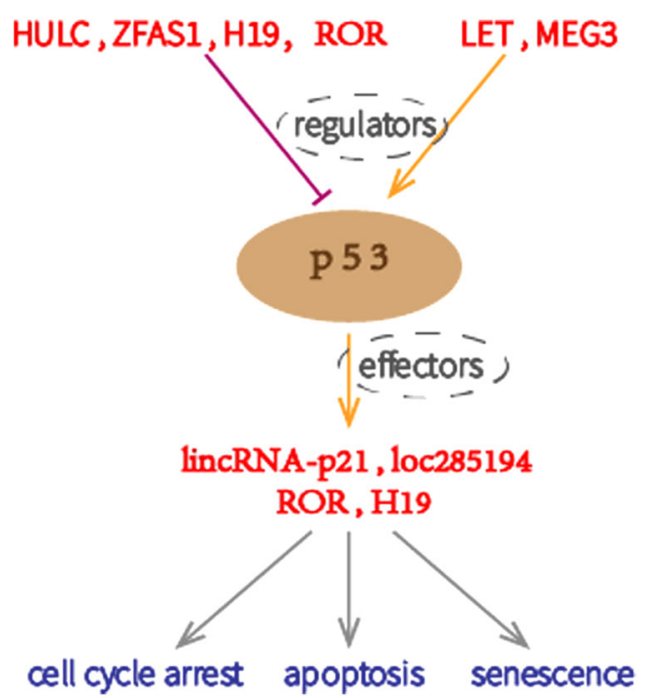

Fig. 2 Proliferation-associated IncRNAs act as p53 regulators or effectors by activating or inhibiting the p53 signaling pathway in its promoter that binds directly to p53. In this way, loc285194 functions as a downstream p53 effector that exerts its anti-proliferative role by binding miR-211 in $\mathrm{CRC}$ and miR-23b in $\mathrm{GC}^{35,36}$. Another representative lncRNA is intergenic lincRNA-p21.

When confronted with DNA damage, the activated p53 signal induces lincRNA-p21, which executes suppressive functions at both the transcriptional and posttranscriptional levels ${ }^{37}$. In the nucleus, lincRNA-p21 promotes its neighboring gene $\mathrm{p} 21$ as an RNA enhancer and downregulates various p53 target genes to facilitate apoptosis by directly binding to hnRNP- $\mathrm{K}^{38}$. In the cytoplasm, however, lincRNA-p21 degrades in an HuRdependent manner to de-repress Rck, which activates $\beta$-catenin and the cell cycle catalyst JunB ${ }^{39,40}$.

Other lncRNAs also regulate p53. The tumor suppressor role of maternally expressed gene 3 (MEG3) and long non-coding RNA-low expression in tumor (lncRNALET) is evident in several gastrointestinal cancers. Data from other studies indicate that the anti-proliferative function of lncRNAs is partially accomplished by activating the p53 pathway ${ }^{41-46}$. In CRC and hepatocellular carcinoma (HCC), zinc finger antisense 1 (ZFAS1) destabilizes p53 to modulate CDK1 and the expression of its partner, cyclin $\mathrm{B} 1$, thus facilitating the $\mathrm{G} 1 / \mathrm{S}$ transition, while highly upregulated in liver cancer (HULC) represses its neighboring eukaryotic translation elongation factor 1 epsilon 1 (EEF1E), which is a pivotal p53 activator and this mechanism promotestumor cell growth ${ }^{47,48}$.

LncRNA-ROR and IncRNA-H19 can be both regulators and effectors of p53 in gastrointestinal cancer proliferation. Overexpressed ROR increases CRC growth by inhibiting p53. Studies have shown that lncRNA-ROR is under the control of p53 in response to DNA damage ${ }^{49,50}$. LncRNA-H19 is only activated by p53 through the HIF pathway in HCC but, in GC, it precludes p53 activity and represses Bax expression to avoid apoptosis ${ }^{51}$.

\section{Akt signaling pathway}

Akt signaling role in tumorigenesis is well established ${ }^{52}$. Activated by growth factors or angiogenesis inducers through receptor tyrosine kinases (RTKs), PI3K phosphorylates PIP2 to produce PIP3, while the phosphatase and tensin homolog deleted on chromosome 10 (PTEN) inhibits this process. Like RTKs, PI3K is also a direct effector of the Ras protein, which provides crosstalk with the MAPK signaling pathway ${ }^{52,53}$. Additionally, protein kinase $\mathrm{B}(\mathrm{PKB} / \mathrm{Akt})$ and mammalian target of rapamycin (mTOR) play crucial roles in cell growth stimulation ${ }^{12}$. By inhibiting the expression of cyclin D1, Bcl-2 antagonist of cell death (Bad), and caspase- 9 by increasing their phosphorylation levels, Akt promotes the G1/S transition and prevents tumor cells from undergoing apoptosis. The concomitant activation of HIF-1 and vascular endothelial 


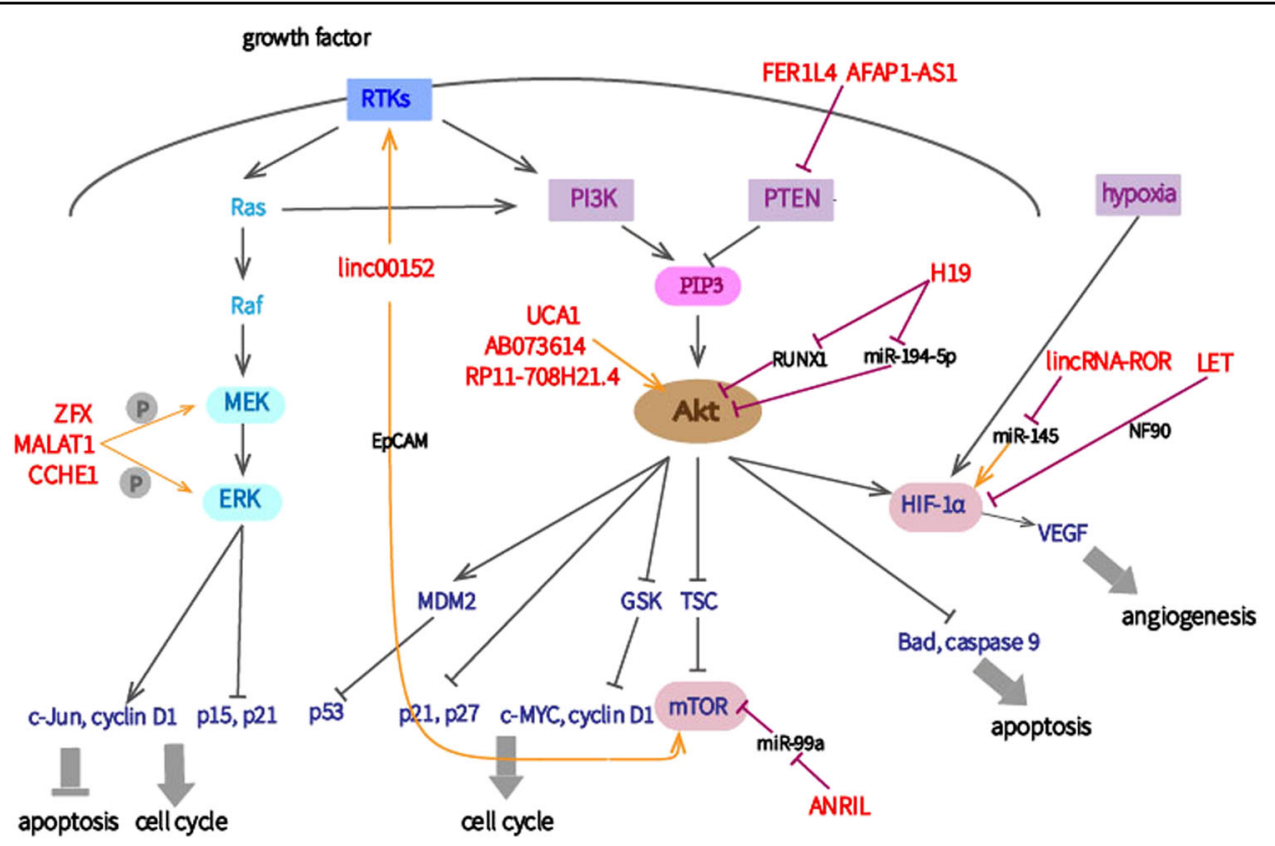

Fig. 3 Proliferation-associated IncRNAs act at specific functional sites of the Akt and MAPK signaling pathways

growth factor (VEGF) corroborate the involvement of Akt in angiogenesis to indirectly facilitate proliferation (Fig. 3) $)^{54,55}$.

Ectopic expression of linc00152 accelerates cell proliferation in many gastrointestinal cancers ${ }^{56}$. Linc00152 directly binds and activates the epithelial growth factor receptor (EGFR), which is a member of the RTK family ${ }^{52,57}$. In HCC, linc00152 activates the PI3K/Akt/ mTOR cascades by binding directly to its neighbor, then TOR-related gene EpCAM through cis-regulation ${ }^{58}$. In gallbladder cancer (GBC), overexpressed linc00152, induced by transcription factor specificity protein 1 (SP1), promotes proliferation via the PI3K/Akt pathway ${ }^{56}$. Another lncRNA, urothelial carcinoma-associated 1 (UCA1), is highly expressed in GC. UCA1 elevates cyclin D1 expression and the G1/S transition by binding directly to EZH2 and promoting interaction with cyclin D1 promoter and also by activating the AKT/GSK3 $3 /$ cyclin D1 axis. Furthermore, EZH2 and phosphorylated Akt can influence the expression of each other to form a positive feedback loop. In conclusion, UCA1 stimulates proliferation by increasing EZH2 and activating the Akt pathway $^{26,27,59}$. In terms of IncRNA-H19, the expression of the tumor suppressor RUNX1 is downregulated by the lncRNA-H19/miR-675 axis to induce Akt/mTOR signal activation; however, in GBC, lncRNA-H19 acts as a ceRNA for miR-194-5p to liberate Akt2 ${ }^{60-62}$.

Like PI3K, PTEN is a well-known regulator of Akt. The pseudogene-derived lncRNA fer-1-like family member 4 (lncRNA-FER1 L4) is strongly downregulated in GC and induces cell cycle arrest. Because FER1 L4 and PTEN mRNA both target miR-106a-5p and because PTEN is a cell cycle inhibitor, it is likely that the anti-proliferative role of FER1 L4 occurs partially through the PTEN/Akt pathway $^{63}$. Upregulated AFAP1-AS1 may mediate GC proliferation and apoptosis by the same mechanism ${ }^{64}$. The lncRNAs AB073614 and RP11-708H21.4 are highly expressed in CRC and stimulate proliferation and hamper apoptosis through the Akt signaling pathway, while the exact IncRNA functional molecules warrant further investigation ${ }^{65,66}$.

\section{MAPK signaling pathway}

Mitogen-activated protein kinases (MAPK) are part of the serine-threonine kinase family and they participate extensively in tumorigenesis. Activation of the MAPK pathway, by phosphorylating MAPK kinases, MEK1/2, and extracellular-signal-regulated kinases (ERK1/2), contributes to perpetual cell growth and survival ${ }^{53}$. ERKs coordinate the synthesis of cyclin D1 and the degradation of the INK4 proteins, such as CDKN1A (p21) and CDKN2B (p15) (Fig. 3) ${ }^{67}$.

MALAT1, which is localized on chromosome 11q13.1, is highly expressed in gastrointestinal cancers. In GBC, the knockdown of MALAT1 significantly impairs the expression of phosphorylated MEK1/2, ERK1/2, and JNK without any changes in quantity, suggesting that this lncRNA is likely to improve GBC proliferation by activating the ERK/MAPK signaling pathway ${ }^{68}$. Upregulated zinc finger protein X-linked (ZFX) and cervical carcinoma 
expressed PCNA regulatory lncRNA (CCHE1) increase cell cycle progression and decrease apoptosis to stimulate proliferation because of their similar mechanisms in GC and HCC, respectively ${ }^{69,70}$. Nevertheless, the direct link between lncRNAs and the MAPK pathway remains enigmatic.

\section{Wnt/ $\beta$-catenin signaling pathway}

The Wnt signaling pathway can be categorized as either canonical or non-canonical based on its downstream components. Here, we focus on the former because of its important role in gastrointestinal cancer initiation and progression ${ }^{71}$. The activation of the canonical Wnt pathway, accurately termed the $\mathrm{Wnt} / \beta$-catenin/TCF signaling pathway, mainly depends on translocation of the central oncogene, $\beta$-catenin. Both negative mutation of adenomatous polyposis coli (APC) oraxin and positive mutation of $\beta$-catenin itself can lead to cytoplasmic accumulation of free $\beta$-catenin and its translocation to the nucleus to bind to $\mathrm{T}$ cell factors (TCFs). Consequently, a series of downstream targets, including c-MYC, cyclin D1, MMP7, and ITF-2, undergo transcriptional activation ${ }^{72}$. LncRNAs interact with critical components of the canonical Wnt pathway and are therefore involved in the regulation of cell proliferation (Fig. 4).

LncRNA colorectal neoplasia differentially expressed (CRNDE) is upregulated in CRC and can act as ceRNA for different miRNAs to promote tumor proliferation. Han et al. demonstrated that $\beta$-catenin and TCF 4 are targets of miR-181a-5p, which inhibits their expression. Similarly, miR-217 modulates transcription factor 7-like 2 (TCF7 L2 ${ }^{73,74}$. Because overexpressed CRNDE hampers specific miRNAs that inhibits $\beta$-catenin, TCFs, c-MYC, and cyclin

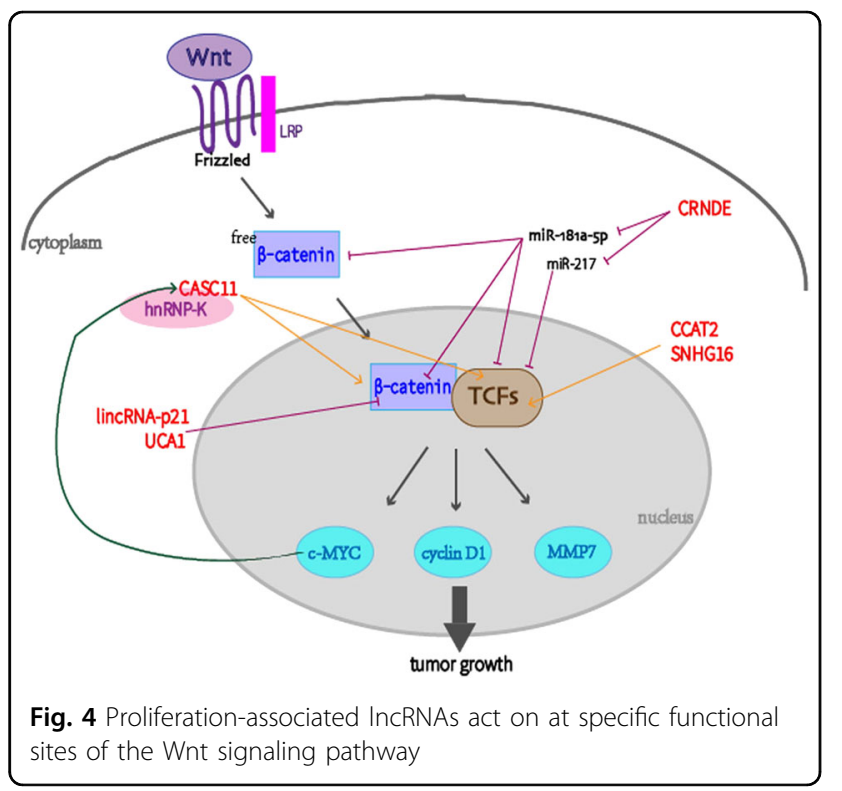

D1, its pro-proliferation function is partially exerted through the Wnt/ $\beta$-catenin pathway.

In addition to inducing miRNA expression, proteins can also serve as bridges between lncRNAs and key components of the Wnt pathway. HnRNP-K, a protein with a nuclear shutting domain (KAS), interacts with $\beta$-catenin and TCF4 to facilitate the import and nuclear accumulation of $\beta$-catenin. A positive feedback loop between CASC11 and hnRNP-K provides an alternative explanation for how the upregulation of CASC11 activates the Wnt/ $\beta$-catenin pathway to stimulate CRC growth through the induction of hnRNP-K. c-MYC, an important target of $\beta$-catenin, increases CASC11 expression through epigenetic regulation ${ }^{75}$.

LncRNAs stimulate the Wnt signaling pathway through direct physical interactions with key effectors. Ling et al. confirmed that CCAT2 increases TCF7 L2 transcriptional activity without affecting its quantity in CRC. Furthermore, CCAT2 is likely to be a downstream target of the Wnt pathway because of the TCF7 L2-binding element within its SNP loci. This positive feedback loop supports the function of highly expressed CCAT2 in CRC growth $^{76}$. Similarly, the combination of lincRNA-p21 and its mRNA target, CTNNB1, precludes the translation of $\beta$-catenin, which suggests that the anti-proliferative role of lincRNA-p21 in CRC is accomplished through the canonical Wnt pathway ${ }^{39}$. The snoRNA host gene 16 (SNHG16) is regulated by Wnt targets, including TCF1, TCF4, and c-MYC, and its knockdown promotes CRC cell death and apoptosis. This presents the possibility that upregulated SNHG16 may stimulate tumor proliferation via the Wnt pathway ${ }^{77}$. Data from Wang et al. demonstrate that the expression of IncRNA UCA1 is reduced in esophageal squamous cell carcinoma (ESCC) and overexpressed UCA1 decreases the levels of the active form of nuclear $\beta$-catenin. So, UCA1 may inhibit ESCC growth through the Wnt/ $\beta$-catenin signaling pathway ${ }^{78}$.

\section{MYC signaling pathway}

The proto-oncogene MYC is frequently upregulated in gastrointestinal cancers, and its gene product is a transcription factor that can accelerate cell proliferation by regulating the expression of genes involved in cell cycle progression $^{79}$. It upregulates the expression of cyclin D and cyclin E, which both promote cell cycle progression. Myc also hampers expression of crucial cyclin/CDK inhibitors, such as CDKN2B (p15), CDKN1A (p21), and CDKN1B (p27) ${ }^{80}$. MYC lies at the crossroads of the pathways involved in regulating cellular proliferation. It is a downstream target of the Wnt, Akt, MAPK, and TGF- $\beta$ signaling cascades and activates the p53 and ARF checkpoints, which makes it even more important to cell growth regulation (Fig. 5b) ${ }^{81}$. LncRNAs both support and repress the pro-proliferative function of MYC by 


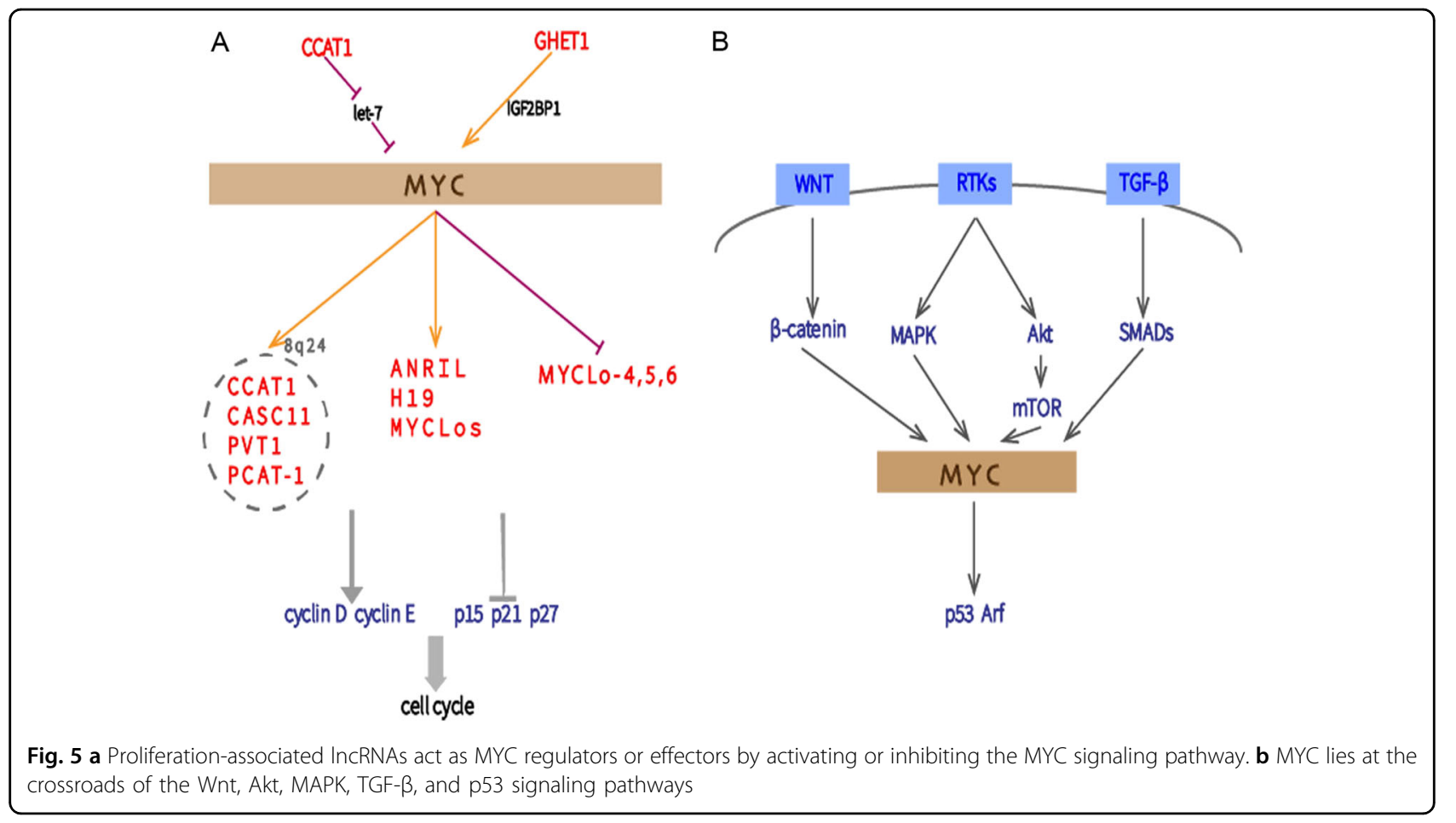

regulating the MYC-target cell cycle modulator genes (Fig. 5a).

Colon cancer-associated transcript 1 (CCAT1), CASC11, plasmacytoma variant translocation 1 (PVT1), and PCAT-1 are lncRNAs that are all localized on the gene desert of chromosome 8q24 and interact with MYC. Among them, CCAT1 and CASC11 can be induced by MYC due to the presence of an E-box Myc-responsive element in their promoters ${ }^{75,82-84}$. In CRC, the PVT1 expression correlates with c-MYC expression levels. Similarly, MYC-related IncRNAs MYCLos are overexpressed in CRC and sustain MYC-driven tumorigenesis. Indeed, MYCLos-1 represses p21, whereas MYCLos-2 (CCAT6) represses p15 by interacting with the $\mathrm{HuR}$ and hnRNP-K proteins, respectively ${ }^{79}$. By binding to the promoter of LncRNA-H19 in GC or of HOTAIR in GBC, c-MYC increases their expression ${ }^{43,85}$. In some instances, MYC can also restrict lncRNA expression. For example, lncRNAs MYCLo-4, -5, and -6, with known tumorsuppressive roles in CRC, are repressed by $\mathrm{MYC}^{86}$.

Notably, MYC can be characterized as a downstream effector of lncRNA. For instance, lncRNA gastric carcinoma high expressed transcript 1 (GHET1) was found to be upregulated in GC. By binding to insulin-like growth factor 2 mRNA-binding protein 1 (IGF2BP1), GHET1 increases the physical interaction between c-Myc mRNA and IGF2BP1, therefore improves the stability of c-Myc mRNA and upregulates its expression. The expression of GHET1 and c-Myc are strongly associated and link with malignant progression in $\mathrm{GC}^{87}$.

\section{Other signaling pathways}

The distribution of regulatory $\mathrm{T}$ cells (T-regs) is highly necessary in immune processes and tumorigenesis. T-reg differentiation, TGF- $\beta$ recruitment, and the subsequent increase in phosphorylated SMAD3 and SMAD2 induced by linc-POU3F3, result in a pro-proliferative role in $\mathrm{GC}^{88}$. Takahashi et al. reported that knockdown of PVT1 in CRC could activate several genes of the TGF- $\beta$ signaling pathway, including SMAD4 and ROCK1. These genes are capable of inducing apoptosis and invasion ${ }^{89}$. Moreover, a feedback loop between TGF- $\beta 1$ and PVT1 in HCC has been suggested, as PVT1 can not only be induced by TGF- $\beta 1$ but, in turn, it also activates the TGF- $\beta$ signaling pathway $^{90}$.

The hypoxia-inducible factor-1 (HIF-1) sustains cell proliferation and survival, and angiogenesis in hypoxic tumor areas. A crosstalk between the HIF-1 pathway and lncRNA network exists ${ }^{6,54}$. LncRNA-ROR sponges miR145 to increase HIF- $1 \alpha$ expression and therefore expression of its downstream target $\mathrm{VEGF}^{49}$. IncRNA-LET stabilizes NF90 (a double-stranded RNA-binding protein) to improve HIF-1 $\alpha$ mRNA stability in GBC, while p53 increases $\mathrm{H} 19$ expression through the HIF signaling pathway in $\mathrm{HCC}^{43,45,51}$.

The previously discussed lncRNA MALAT1, which is overexpressed in ESCC, induces dephosphorylation of the ATM/CHK2 pathway thereby overcoming the G2/M cell cycle checkpoint ${ }^{91}$. In addition, MEG3 and lincRNA-p21 contribute to apoptosis and growth inhibition through endoplasmic reticulum (ER) stress pathways in ESCC and 
HCC, respectively ${ }^{39,92}$. In GC, lncRNA gastric cancerassociated transcript 3 (GACAT3) works as a downstream target of IL6/STAT3 signaling pathway to accomplish its function $^{93}$.

\section{Conclusions}

Although advancements in surveying the molecular mechanisms underlying the actions of proliferationassociated IncRNAs have broadened our ability to annotate these tumor-related transcripts, the exact signaling pathways in which many lncRNAs participate remain unclearly defined. The major signaling cascades and specific functional sites reviewed here may provide a foundation upon which new lncRNAs involved in gastrointestinal tumor proliferation can be identified and may motivate an increased focus on understanding the signaling pathways, which remain enigmatic. Malignant cell growth can be non-comprehensive because it can be caused by any of several dysregulated cellular processes, such as the cell cycle, apoptosis, angiogenesis, and cell senescence; it is likely that the lncRNAs described here are important regulators of these pathophysiological processes. Consequently, lncRNAs characterized as oncogenes or tumor suppressors that modulate proliferation may be promising biomarkers and therapeutic targets in gastrointestinal cancers ${ }^{41,94-170}$.

\section{Acknowledgements}

This study was supported by the National Natural Science Foundation of China (81372622 and 81672362), the Natural Science Foundation of Zhejiang Province (LQ17H160009), and the Zhejiang Province Medical Science and Technology Project (2018276694).

\section{Conflict of interest}

The authors declare that they have no conflict of interest.

\section{Publisher's note}

Springer Nature remains neutral with regard to jurisdictional claims in published maps and institutional affiliations.

Supplementary Information accompanies this paper at https://doi.org/ 10.1038/s41420-018-0051-8.

Received: 28 January 2018 Revised: 14 March 2018 Accepted: 19 March 2018

Published online: 27 April 2018

\section{References}

1. Kung, J. T., Colognori, D. \& Lee, J. T. Long noncoding RNAs: past, present, and future. Genetics 193, 651-669 (2013).

2. Eddy, S. R. Non-coding RNA genes and the modern RNA world. Nat. Rev. Genet. 2, 919-929 (2001).

3. Tano, K. \& Akimitsu, N. Long non-coding RNAs in cancer progression. Front. Genet. 3, 219 (2012).

4. Chen, W. et al. Cancer statistics in China, 2015. CA Cancer J. Clin. 66, 115-132 (2016)

5. Torre, L. A. et al. Global cancer statistics, 2012. CA Cancer J. Clin. 65, 87-108 (2015).
6. Hanahan, D. \& Weinberg, R. A. Hallmarks of cancer: the next generation. Cell 144, 646-674 (2011).

7. Noatynska, A., Tavernier, N., Gotta, M. \& Pintard, L. Coordinating cell polarity and cell cycle progression: what can we learn from flies and worms? Open Biol. 3, 130083 (2013).

8. Soufi, A. \& Dalton, S. Cycling through developmental decisions: how cell cycle dynamics control pluripotency, differentiation and reprogramming. Development 143, 4301-4311 (2016).

9. Kapinas, K. et al. The abbreviated pluripotent cell cycle. J. Cell. Physiol. 228 9-20 (2013).

10. Nagano, T. \& Fraser, P. No-nonsense functions for long noncoding RNAs. Cell 145, 178-181 (2011).

11. Lee, J. T. Epigenetic regulation by long noncoding RNAs. Science $\mathbf{3 3 8}$ 1435-1439 (2012).

12. Tay, Y., Rinn, J. \& Pandolfi, P. P. The multilayered complexity of ceRNA crosstalk and competition. Nature 505, 344-352 (2014).

13. Salmena, L., Poliseno, L., Tay, Y., Kats, L. \& Pandolfi, P. P. A ceRNA hypothesis: the Rosetta Stone of a hidden RNA language? Cell 146, 353-358 (2011).

14. Guo, L. L. et al. Competing endogenous RNA networks and gastric cancer. World J. Gastroenterol. 21, 11680-11687 (2015).

15. Paraskevopoulou, M. D. et al. DIANA-LncBase: experimentally verified and computationally predicted microRNA targets on long non-coding RNAs. Nucleic Acids Res. 41, D239-245 (2013).

16. Friedman, R. C., Farh, K. K., Burge, C. B. \& Bartel, D. P. Most mammalian mRNAs are conserved targets of microRNAs. Genome Res. 19, 92-105 (2009).

17. Filipowicz, W., Bhattacharyya, S. N. \& Sonenberg, N. Mechanisms of posttranscriptional regulation by microRNAs: are the answers in sight? Nat. Rev. Genet. 9, 102-114 (2008).

18. Yoshimoto, R., Mayeda, A., Yoshida, M. \& Nakagawa, S. MALAT1 long noncoding RNA in cancer. Biochim. Biophys. Acta 1859, 192-199 (2016).

19. Wang, J. et al. MALAT1 promotes cell proliferation in gastric cancer by recruiting SF2/ASF. Biomed. Pharmacother. 68, 557-564 (2014).

20. Batista, P. J. \& Chang, H. Y. Long noncoding RNAs: cellular address codes in development and disease. Cell 152, 1298-1307 (2013).

21. Huang, B. et al. Long non-coding antisense RNA KRT7-AS is activated in gastric cancers and supports cancer cell progression by increasing KRT7 expression. Oncogene 35, 4927-4936 (2016).

22. Schmitt, A. M. \& Chang, H. Y. Long noncoding RNAs in cancer pathways. Cancer Cell 29, 452-463 (2016).

23. Kouzarides, T. Chromatin modifications and their function. Cell 128, 693-705 (2007).

24. Simon, J. A. \& Kingston, R. E. Mechanisms of polycomb gene silencing: knowns and unknowns. Nat. Rev. Mol. Cell Biol. 10, 697-708 (2009).

25. Jin, Y. et al. LSD1 collaborates with EZH2 to regulate expression of interferonstimulated genes. Biomed. Pharmacother. 88, 728-737 (2017).

26. Cao, W. et al. Up-regulation of enhancer of zeste homolog 2 is associated positively with cyclin D1 overexpression and poor clinical outcome in head and neck squamous cell carcinoma. Cancer 118, 2858-2871 (2012).

27. Wang, Z. Q. et al. Long noncoding RNA UCA1 induced by SP1 promotes cell proliferation via recruiting EZH2 and activating AKT pathway in gastric cancer. Cell Death Dis. 8, e2839 (2017).

28. Sun, T. T. et al. LncRNA GClnc1 promotes gastric carcinogenesis and may act as a modular scaffold of WDR5 and KAT2A complexes to specify the histone modification pattern. Cancer Discov. 6, 784-801 (2016).

29. Wang, K. C. \& Chang, H. Y. Molecular mechanisms of long noncoding RNAs. Mol. Cell 43, 904-914 (2011).

30. Rinn, J. L. \& Chang, H. Y. Genome regulation by long noncoding RNAs. Annu. Rev. Biochem. 81, 145-166 (2012).

31. Taniue, $\mathrm{K}$. et al. Long noncoding RNA UPAT promotes colon tumorigenesis by inhibiting degradation of UHRF1. Proc. Natl Acad. Sci. USA 113, 1273-1278 (2016).

32. Bieging, K. T., Mello, S. S. \& Attardi, L. D. Unravelling mechanisms of p53mediated tumour suppression. Nat. Rev. Cancer 14, 359-370 (2014).

33. Huarte, M. et al. A large intergenic noncoding RNA induced by p53 mediates global gene repression in the p53 response. Cell 142, 409-419 (2010).

34. Zhang, A., Xu, M. \& Mo, Y. Y. Role of the IncRNA-p53 regulatory network in cancer. J. Mol. Cell Biol. 6, 181-191 (2014).

35. Liu, Q. et al. LncRNA loc285194 is a p53-regulated tumor suppressor. Nucleic Acids Res. 41, 4976-4987 (2013).

36. Qi, P. et al. Reciprocal repression between TUSC7 and miR-23b in gastric cancer. Int. J. Cancer 137, 1269-1278 (2015). 
37. Chaudhary, R. \& Lal, A. Long noncoding RNAs in the p53 network. Wiley Interdiscip. Rev. RNA 8, e1410 (2017).

38. Grossi, E., Sanchez, Y. \& Huarte, M. Expanding the p53 regulatory network: LncRNAs take up the challenge. Biochim. Biophys. Acta 1859, 200-208 (2016).

39. Chen, S. et al. LincRNa-p21: function and mechanism in cancer. Med. Oncol. 34, 98 (2017).

40. Yoon, J. H. et al. LincRNA-p21 suppresses target mRNA translation. Mol. Cell 47, 648-655 (2012)

41. Zhuo, $\mathrm{H}$. et al. The aberrant expression of MEG3 regulated by UHRF1 predicts the prognosis of hepatocellular carcinoma. Mol. Carcinog. 55, 209-219 (2016).

42. Braconi, $\mathrm{C}$. et al. microRNA-29 can regulate expression of the long noncoding RNA gene MEG3 in hepatocellular cancer. Oncogene 30, 4750-4756 (2011).

43. Khandelwal, A., Malhotra, A., Jain, M., Vasquez, K. M. \& Jain, A. The emerging role of long non-coding RNA in gallbladder cancer pathogenesis. Biochimie 132, 152-160 (2017).

44. Wang, P. L. et al. Long non-coding RNA-low expression in tumor inhibits the invasion and metastasis of esophageal squamous cell carcinoma by regulating p53 expression. Mol. Med. Rep. 13, 3074-3082 (2016).

45. Yang, F. et al. Repression of the long noncoding RNA-LET by histone deacetylase 3 contributes to hypoxia-mediated metastasis. Mol. Cell 49, 1083-1096 (2013).

46. Tian, J. et al. Identification of the long noncoding RNA LET as a novel tumor suppressor in gastric cancer. Mol. Med. Rep. 15, 2229-2234 (2017).

47. Thorenoor, N. et al. Long non-coding RNA ZFAS1 interacts with CDK1 and is involved in p53-dependent cell cycle control and apoptosis in colorectal cancer. Oncotarget 7, 622-637 (2016).

48. Yu, X., Zheng, H., Chan, M. T. \& Wu, W. K. HULC: an oncogenic long noncoding RNA in human cancer. J. Cell. Mol. Med. 21, 410-417 (2017).

49. Pan, Y. et al. The emerging roles of long noncoding RNA ROR (lincRNA-ROR) and its possible mechanisms in human cancers. Cell. Physiol. Biochem. 40, 219-229 (2016).

50. Li, H., Jiang, X. \& Niu, X. Long non-coding RNA reprogramming (ROR) promotes cell proliferation in colorectal cancer via affecting P53. Med. Sci. Monit. 23, 919-928 (2017).

51. Zhang, L. et al. The interplay of LnCRNA-H19 and its binding partners in physiological process and gastric carcinogenesis. Int. J. Mol. Sci. 18, 450 (2017).

52. Khan, K. H., Yap, T. A., Yan, L. \& Cunningham, D. Targeting the PI3K-AKT-mTOR signaling network in cancer. Chin. J. Cancer 32, 253-265 (2013).

53. De Luca, A., Maiello, M. R., D’Alessio, A., Pergameno, M. \& Normanno, N. The RAS/RAF/MEK/ERK and the PI3KJAKT signalling pathways: role in cancer pathogenesis and implications for therapeutic approaches. Expert Opin. Ther. Targets 16, S17-27 (2012).

54. Sasaki, T. \& Kuniyasu, H. Significance of AKT in gastric cancer (Review). Int. J. Oncol. 45, 2187-2192 (2014).

55. Tokunaga, E. et al. Deregulation of the Akt pathway in human cancer. Curr. Cancer Drug Targets 8, 27-36 (2008).

56. Yu, Y. et al. LINC00152: a pivotal oncogenic long non-coding RNA in human cancers. Cell Prolif. 50, e12349 (2017).

57. Zhou, J. et al. Linc00152 promotes proliferation in gastric cancer through the EGFR-dependent pathway. J. Exp. Clin. Cancer Res. 34, 135 (2015).

58. Ji, J. et al. LINC00152 promotes proliferation in hepatocellular carcinoma by targeting EpCAM via the mTOR signaling pathway. Oncotarget 6, 42813-42824 (2015).

59. Geng, J. et al. EZH2 promotes tumor progression via regulating VEGF-A/AKT signaling in non-small cell lung cancer. Cancer Lett. 359, 275-287 (2015).

60. Liu, G., Xiang, T., Wu, Q. F. \& Wang, W. X. Long noncoding RNA H19-derived miR-675 enhances proliferation and invasion via RUNX1 in gastric cancer cells. Oncol. Res. 23, 99-107 (2016).

61. Zhuang, M., Gao, W., Xu, J., Wang, P. \& Shu, Y. The long non-coding RNA H19derived miR-675 modulates human gastric cancer cell proliferation by targeting tumor suppressor RUNX1. Biochem. Biophys. Res. Commun. 448, 315-322 (2014).

62. Wang, S. H. et al. Long noncoding RNA H19 contributes to gallbladder cancer cell proliferation by modulated miR-194-5p targeting AKT2. Tumour Biol. 37, 9721-9730 (2016).

63. Xia, T. et al. Long noncoding RNA FER1L4 suppresses cancer cell growth by acting as a competing endogenous RNA and regulating PTEN expression. Sci. Rep. 5, 13445 (2015).
64. Guo, J. Q., Li, S. J. \& Guo, G. X. Long noncoding RNA AFAP1-AS1 promotes cell proliferation and apoptosis of gastric cancer cells via PTEN/p-AKT pathway. Dig. Dis. Sci. 62, 2004-2010 (2017).

65. Wang, Y. et al. LncRNA AB073614 regulates proliferation and metastasis of colorectal cancer cells via the PI3KJAKT signaling pathway. Biomed. Pharmacother. 93, 1230-1237 (2017).

66. Sun, L. et al. Down-regulation of long non-coding RNA RP11-708H21.4 is associated with poor prognosis for colorectal cancer and promotes tumorigenesis through regulating AKT/mTOR pathway. Oncotarget 8, 27929-27942 (2017).

67. Fang, J. Y. \& Richardson, B. C. The MAPK signalling pathways and colorectal cancer. Lancet Oncol. 6, 322-327 (2005).

68. Wu, X. S. et al. MALAT1 promotes the proliferation and metastasis of gallbladder cancer cells by activating the ERK/MAPK pathway. Cancer Biol. Ther. 15, 806-814 (2014).

69. Peng, W. \& Fan, H. Long noncoding RNA CCHE1 indicates a poor prognosis of hepatocellular carcinoma and promotes carcinogenesis via activation of the ERK/MAPK pathway. Biomed. Pharmacother. 83, 450-455 (2016).

70. $\mathrm{Wu}, \mathrm{S}$. et al. Knockdown of ZFX inhibits gastric cancer cell growth in vitro and in vivo via downregulating the ERK-MAPK pathway. Cancer Lett. 337, 293-300 (2013).

71. Doucas, H., Garcea, G., Neal, C. P., Manson, M. M. \& Berry, D. P. Changes in the Wnt signalling pathway in gastrointestinal cancers and their prognostic significance. Eur. J. Cancer 41, 365-379 (2005).

72. Kolligs, F. T., Bommer, G. \& Goke, B. Wnt/beta-catenin/tcf signaling: a critical pathway in gastrointestinal tumorigenesis. Digestion 66, 131-44 (2002).

73. Yu, B. et al. The long non-coding RNA CRNDE promotes colorectal carcinoma progression by competitively binding miR-217 with TCF7L2 and enhancing the Wnt/beta-catenin signaling pathway. Cell. Physiol. Biochem. 41, 2489-2502 (2017).

74. Han, P. et al. The IncRNA CRNDE promotes colorectal cancer cell proliferation and chemoresistance via miR-181a-5p-mediated regulation of Wnt/betacatenin signaling. Mol. Cancer 16, 9 (2017).

75. Zhang, Z. et al. Long non-coding RNA CASC11 interacts with hnRNP-K and activates the WNT/ $\beta$-catenin pathway to promote growth and metastasis in colorectal cancer. Cancer Lett. 376, 62-73 (2016).

76. Ling, $\mathrm{H}$. et al. CCAT2, a novel noncoding RNA mapping to $8 \mathrm{q} 24$, underlies metastatic progression and chromosomal instability in colon cancer. Genome Res. 23, 1446-1461 (2013).

77. Christensen, L. L. et al. SNHG16 is regulated by the Wnt pathway in colorectal cancer and affects genes involved in lipid metabolism. Mol. Oncol. 10, 1266-1282 (2016).

78. Wang, $X$. et al. IncRNA UCA1 inhibits esophageal squamous-cell carcinoma growth by regulating the Wnt signaling pathway. J. Toxicol. Environ. Health $A$ 79, 407-418 (2016).

79. Kim, T. et al. Role of MYC-regulated long noncoding RNAs in cell cycle regulation and tumorigenesis. J. Natl Cancer Inst. 107, dju505 (2015).

80. Gandarillas, A. The mysterious human epidermal cell cycle, or an oncogeneinduced differentiation checkpoint. Cell Cycle 11, 4507-4516 (2012).

81. Wan, $X$. et al. The functional sites of miRNAs and IncRNAs in gastric carcinogenesis. Tumour Biol. 36, 521-532 (2015).

82. Zhou, D. D., Liu, X. F., Lu, C. W., Pant, O. P. \& Liu, X. D. Long non-coding RNA PVT1: emerging biomarker in digestive system cancer. Cell Prolif. 50, e12398 (2017).

83. Qiao, L. et al. Down regulation of the long non-coding RNA PCAT-1 induced growth arrest and apoptosis of colorectal cancer cells. Life Sci. 188, 37-44 (2017).

84. Xin, Y., Li, Z., Shen, J., Chan, M. T. \& Wu, W. K. CCAT1: a pivotal oncogenic long non-coding RNA in human cancers. Cell Prolif. 49, 255-260 (2016).

85. Zhang, E. B. et al. c-Myc-induced, long, noncoding H19 affects cell proliferation and predicts a poor prognosis in patients with gastric cancer. Med. Oncol. 31, 914 (2014).

86. Kim, T. et al. MYC-repressed long noncoding RNAs antagonize MYC-induced cell proliferation and cell cycle progression. Oncotarget 6, 18780-18789 (2015).

87. Yang, F. et al. Long non-coding RNA GHET1 promotes gastric carcinoma cell proliferation by increasing c-Myc mRNA stability. FEBS J. 281, 802-813 (2014).

88. Xiong, G., Yang, L., Chen, Y. \& Fan, Z. Linc-POU3F3 promotes cell proliferation in gastric cancer via increasing T-reg distribution. Am. J. Transl. Res. 7, 2262-2269 (2015). 
89. Takahashi, Y. et al. Amplification of PVT-1 is involved in poor prognosis via apoptosis inhibition in colorectal cancers. Br. J. Cancer 110, 164-171 (2014).

90. Wang, F. et al. Oncofetal long noncoding RNA PVT1 promotes proliferation and stem cell-like property of hepatocellular carcinoma cells by stabilizing NOP2. Hepatology 60, 1278-1290 (2014).

91. Hu, L. et al. Up-regulation of long noncoding RNA MALAT1 contributes to proliferation and metastasis in esophageal squamous cell carcinoma. J. Exp. Clin. Cancer Res. 34, 7 (2015).

92. Huang, Z. L. et al. Long non-coding RNA MEG3 induces cell apoptosis in esophageal cancer through endoplasmic reticulum stress. Oncol. Rep. 37, 3093-3099 (2017).

93. Shen, W. et al. Novel long non-coding RNA GACAT3 promotes gastric cancer cell proliferation through the IL-6/STAT3 signaling pathway. Tumour Biol. $\mathbf{3 7}$ 14895-14902 (2016).

94. Guo, K. et al. The expression pattern of long non-coding RNA PVT1 in tumor tissues and in extracellular vesicles of colorectal cancer correlates with cancer progression. Tumour Biol. 39, 1010428317699122 (2017).

95. Jin, J., Chu, Z., Ma, P., Meng, Y. \& Yang, Y. Long non-coding RNA SPRY4-IT1 promotes proliferation and invasion by acting as a ceRNA of miR-101-3p in colorectal cancer cells. Tumour Biol. 39, 1010428317716250 (2017).

96. Zhou, M., Zhang, X. Y. \& Yu, X. Overexpression of the long non-coding RNA SPRY4-IT1 promotes tumor cell proliferation and invasion by activating EZH2 in hepatocellular carcinoma. Biomed. Pharmacother. 85, 348-354 (2017).

97. Peng, W., Wu, G., Fan, H., Wu, J. \& Feng, J. Long noncoding RNA SPRY4-IT1 predicts poor patient prognosis and promotes tumorigenesis in gastric cancer. Tumour Biol. 36, 6751-6758 (2015).

98. Cui, F. et al. Long noncoding RNA SPRY4-IT1 promotes esophageal squamous cell carcinoma cell proliferation, invasion, and epithelial-mesenchymal transition. Tumour Biol. 37, 10871-10876 (2016)

99. Zhang, E. et al. H3K27 acetylation activated-long non-coding RNA CCAT1 affects cell proliferation and migration by regulating SPRY4 and HOXB13 expression in esophageal squamous cell carcinoma. Nucleic Acids Res. 45, 3086-3101 (2017).

100. Xin, Y., Li, Z., Zheng, H., Chan, M. T. V. \& Ka Kei Wu, W. CCAT2: a novel oncogenic long non-coding RNA in human. Cell Prolif. 50, e12342 (2017).

101. Ding, J. et al. Long noncoding RNA CRNDE promotes colorectal cancer cell proliferation via epigenetically silencing DUSP5/CDKN1A expression. Cell Death Dis. 8, e2997 (2017).

102. Hu, C. E., Du, P. Z., Zhang, H. D. \& Huang, G. J. Long noncoding RNA CRNDE promotes proliferation of gastric cancer cells by targeting miR-145. Cell. Physiol. Biochem. 42, 13-21 (2017).

103. Zhou, X. et al. The interaction between MiR-141 and IncRNA-H19 in regulating cell proliferation and migration in gastric cancer. Cell. Physiol. Biochem. 36, 1440-1452 (2015)

104. Ohtsuka, M. et al. H19 noncoding RNA, an independent prognostic factor, regulates essential Rb-E2F and CDK8-beta-catenin signaling in colorectal cancer. EBioMedicine 13, 113-124 (2016).

105. Tsang, W. P. et al. Oncofetal H19-derived miR-675 regulates tumor suppressor RB in human colorectal cancer. Carcinogenesis 31, 350-358 (2010).

106. Zhao, Y. et al. Role of long non-coding RNA HULC in cell proliferation, apoptosis and tumor metastasis of gastric cancer: a clinical and in vitro investigation. Oncol. Rep. 31, 358-364 (2014)

107. Yang, X. J., Huang, C. Q., Peng, C. W., Hou, J. X. \& Liu, J. Y. Long noncoding RNA HULC promotes colorectal carcinoma progression through epigenetically repressing NKD2 expression. Gene 592, 172-178 (2016)

108. Nie, F. et al. Long noncoding RNA ZFAS1 promotes gastric cancer cells proliferation by epigenetically repressing KLF2 and NKD2 expression. Oncotarget 8, 38227-38238 (2017).

109. Han, Y. et al. UCA1, a long non-coding RNA up-regulated in colorectal cancer influences cell proliferation, apoptosis and cell cycle distribution. Pathology 46, 396-401 (2014)

110. Zheng, Q. et al. Aberrant expression of UCA1 in gastric cancer and its clinical significance. Clin. Transl. Oncol. 17, 640-646 (2015).

111. Fu, X. L. et al. Analysis of long non-coding RNA expression profiles in pancreatic ductal adenocarcinoma. Sci. Rep. 6, 33535 (2016).

112. Liu, X. H. et al. LncRNA HOTAIR functions as a competing endogenous RNA to regulate HER2 expression by sponging miR-331-3p in gastric cancer. Mol. Cancer 13, 92 (2014).

113. Wang, S. H. et al. The InCRNA MALAT1 functions as a competing endogenous RNA to regulate MCL-1 expression by sponging miR-363-3p in gallbladder cancer. J. Cell. Mol. Med. 20, 2299-2308 (2016).
114. Ji, Q. et al. Long non-coding RNA MALAT1 promotes tumour growth and metastasis in colorectal cancer through binding to SFPQ and releasing oncogene PTBP2 from SFPQ/PTBP2 complex. Br. J. Cancer 111, 736-748 (2014).

115. Li, C. et al. Progress and prospects of long noncoding RNAs (IncRNAs) in hepatocellular carcinoma. Cell. Physiol. Biochem. 36, 423-434 (2015).

116. Liu, Y. R. et al. Long noncoding RNAs in hepatocellular carcinoma: novel insights into their mechanism. World J. Hepatol. 7, 2781-2791 (2015).

117. Bao, H. \& Su, H. Long noncoding RNAs act as novel biomarkers for hepatocellular carcinoma: progress and prospects. Biomed. Res. Int. 2017, 6049480 (2017).

118. Wang, $X$. et al. Silencing of long noncoding RNA MALAT1 by miR-101 and miR-217 inhibits proliferation, migration, and invasion of esophageal squamous cell carcinoma cells. J. Biol. Chem. 290, 3925-3935 (2015).

119. Huang, M. et al. Long noncoding RNA LINC00673 is activated by SP1 and exerts oncogenic properties by interacting with LSD1 and EZH2 in gastric cancer. Mol. Ther. 25, 1014-1026 (2017).

120. Pan, F. et al. A novel long non-coding RNA FOXCUT and mRNA FOXC1 pair promote progression and predict poor prognosis in esophageal squamous cell carcinoma. Int. J. Clin. Exp. Pathol. 7, 2838-2849 (2014).

121. Wang, C. M. et al. Upregulation of the long non-coding RNA PIncRNA-1 promotes esophageal squamous carcinoma cell proliferation and correlates with advanced clinical stage. Dig. Dis. Sci. 59, 591-597 (2014).

122. Zhang, E. B. et al. Long noncoding RNA ANRIL indicates a poor prognosis of gastric cancer and promotes tumor growth by epigenetically silencing of miR-99a/miR-449a. Oncotarget 5, 2276-2292 (2014).

123. Peng, W. \& Fan, H. Long non-coding RNA PANDAR correlates with poor prognosis and promotes tumorigenesis in hepatocellular carcinoma. Biomed. Pharmacother. 72, 113-118 (2015)

124. Li, J. et al. PANDAR: a pivotal cancer-related long non-coding RNA in human cancers. Mol. Biosyst. 13, 2195-2201 (2017).

125. Li, Z., Shen, J., Chan, M. T. \& Wu, W. K. TUG1: a pivotal oncogenic long noncoding RNA of human cancers. Cell Prolif. 49, 471-475 (2016).

126. Zhang, E. et al. Increased expression of long noncoding RNA TUG1 predicts a poor prognosis of gastric cancer and regulates cell proliferation by epigenetically silencing of p57. Cell Death Dis. 7, e2109 (2016).

127. Zhai, H. Y. et al. Overexpression of long non-coding RNA TUG1 promotes colon cancer progression. Med. Sci. Monit. 22, 3281-3287 (2016).

128. Ma, F. et al. Long non-coding RNA TUG1 promotes cell proliferation and metastasis by negatively regulating miR-300 in gallbladder carcinoma. Biomed. Pharmacother. 88, 863-869 (2017).

129. Yang, $\mathrm{P}$. et al. The long noncoding RNA-ROR promotes the resistance of radiotherapy for human colorectal cancer cells by targeting the p53/miR-145 pathway. J. Gastroenterol. Hepatol. 32, 837-845 (2017).

130. Zhou, P., Sun, L., Liu, D., Liu, C. \& Sun, L. Long non-coding RNA lincRNA-ROR promotes the progression of colon cancer and holds prognostic value by associating with miR-145. Pathol. Oncol. Res. 22, 733-740 (2016).

131. Zang, W. et al. Long noncoding RNA PEG10 regulates proliferation and invasion of esophageal cancer cells. Cancer Gene Ther. 22, 138-144 (2015).

132. Xu, M. D. et al. Long non-coding RNA LSINCT5 predicts negative prognosis and exhibits oncogenic activity in gastric cancer. Medicine 93, e303 (2014).

133. Zhou, J. et al. Knockdown of long noncoding RNA GHET1 inhibits cell proliferation and invasion of colorectal cancer. Oncol. Res. 23, 303-309 (2016).

134. Chen, W. M. et al. Antisense long noncoding RNA HIF1A-AS2 Is upregulated in gastric cancer and associated with poor prognosis. Dig. Dis. Sci. 60, 1655-1662 (2015).

135. Hu, Y., Pan, J., Wang, Y., Li, L. \& Huang, Y. Long noncoding RNA linc-UBC1 is negative prognostic factor and exhibits tumor pro-oncogenic activity in gastric cancer. Int. J. Clin. Exp. Pathol. 8, 594-600 (2015).

136. Shi, W. H. et al. Upregulation of the long noncoding RNA PCAT-1 correlates with advanced clinical stage and poor prognosis in esophageal squamous carcinoma. Tumour Biol. 36, 2501-2507 (2015).

137. Xie, M. et al. Long noncoding RNA HOXA-AS2 promotes gastric cancer proliferation by epigenetically silencing P21/PLK3/DDIT3 expression. Oncotarget 6, 33587-33601 (2015).

138. Li, W. et al. Increased levels of the long intergenic non-protein coding RNA POU3F3 promote DNA methylation in esophageal squamous cell carcinoma cells. Gastroenterology 146, 1714-1726 (2014).

139. Chen, S. X. et al. Upregulated expression of long noncoding RNA SNHG15 promotes cell proliferation and invasion through regulates MMP2/MMP9 in patients with GC. Tumour Biol. 37, 6801-6812 (2016). 
140. Lian, Y. et al. The long noncoding RNA HOXA transcript at the distal tip promotes colorectal cancer growth partially via silencing of p21 expression. Tumour Biol. 37, 7431-7440 (2016).

141. Zhang, F. et al. AFAP1-AS1: a novel oncogenic long non-coding RNA in human cancers. Cell Prolif. 51, e12397 (2018).

142. Qi, F. et al. Long noncoding AGAP2-AS1 is activated by SP1 and promotes cell proliferation and invasion in gastric cancer. J. Hematol. Oncol. 10, 48 (2017).

143. Li, J. et al. Long non-coding RNA FOXP4-AS1 is an unfavourable prognostic factor and regulates proliferation and apoptosis in colorectal cancer. Cell Prolif. 50, e12312 (2017).

144. Niu, H. et al. Long non-coding RNA AK027294 involves in the process of proliferation, migration, and apoptosis of colorectal cancer cells. Tumour Biol. 37, 10097-10105 (2016)

145. Wu, X. et al. Long non-coding RNA ucoo2kmd.1 regulates CD44-dependent cell growth by competing for miR-211-3p in colorectal cancer. PLOS ONE 11, e0151287 (2016).

146. $\mathrm{Xu}$, Y. et al. Long noncoding RNA, tissue differentiation-inducing nonprotein coding RNA is upregulated and promotes development of esophageal squamous cell carcinoma. Dis. Esophagus 29, 950-958 (2016).

147. Yang, L. et al. Upregulation of long non-coding RNA PRNCR1 in colorectal cancer promotes cell proliferation and cell cycle progression. Oncol. Rep. 35 318-324 (2016).

148. Shi, D. et al. Silencing of long non-coding RNA SBDSP1 suppresses tumor growth and invasion in colorectal cancer. Biomed. Pharmacother. 85, 355-361 (2017).

149. Han, Y. et al. LEIGC long non-coding RNA acts as a tumor suppressor in gastric carcinoma by inhibiting the epithelial-to-mesenchymal transition. BMC Cancer 14, 932 (2014).

150. Sun, M. et al. Decreased expression of long noncoding RNA GAS5 indicates a poor prognosis and promotes cell proliferation in gastric cancer. BMC Cancer 14, 319 (2014).

151. Yin, D. et al. Long noncoding RNA GAS5 affects cell proliferation and predicts a poor prognosis in patients with colorectal cancer. Med. Oncol. 31, 253 (2014)

152. Chang, $L$. et al. Decreased expression of long non-coding RNA GAS5 indicates a poor prognosis and promotes cell proliferation and invasion in hepatocellular carcinoma by regulating vimentin. Mol. Med. Rep. 13 1541-1550 (2016).

153. Yan, J. et al. MiR-148a regulates MEG3 in gastric cancer by targeting DNA methyltransferase 1. Med. Oncol. 31, 879 (2014).

154. Peng, W. et al. Long non-coding RNA MEG3 functions as a competing endogenous RNA to regulate gastric cancer progression. J. Exp. Clin. Cancer Res. 34, 79 (2015).
155. Sun, M. et al. Downregulated long noncoding RNA MEG3 is associated with poor prognosis and promotes cell proliferation in gastric cancer. Tumour Biol. 35, 1065-1073 (2014).

156. Yin, D. D. et al. Decreased expression of long noncoding RNA MEG3 affects cell proliferation and predicts a poor prognosis in patients with colorectal cancer. Tumour Biol. 36, 4851-4859 (2015).

157. Ding, J. et al. Long non-coding RNA Loc554202 induces apoptosis in colorectal cancer cells via the caspase cleavage cascades. J. Exp. Clin. Cancer Res. 34, 100 (2015).

158. Du, T. et al. Decreased expression of long non-coding RNA WT1-AS promotes cell proliferation and invasion in gastric cancer. Biochim. Biophys. Acta 1862, 12-19 (2016).

159. Li, Y. et al. Decreased expression of LncRNA SLC25A25-AS1 promotes proliferation, chemoresistance, and EMT in colorectal cancer cells. Tumour Biol. 37, 14205-14215 (2016).

160. Fei, Z. H. et al. Upregulated expression of long non-coding RNA LINC00982 regulates cell proliferation and its clinical relevance in patients with gastric cancer. Tumour Biol. 37, 1983-1993 (2016).

161. Guo, W. et al. Aberrant methylation-mediated downregulation of long noncoding RNA LOC100130476 correlates with malignant progression of esophageal squamous cell carcinoma. Dig. Liver Dis. 48, 961-969 (2016).

162. Nie, F. Q. et al. Decreased long noncoding RNA MIR31HG is correlated with poor prognosis and contributes to cell proliferation in gastric cancer. Tumour Biol. 37, 7693-7701 (2016).

163. Cao, Y. et al. p53-inducible long non-coding RNA PICART1 mediates cancer cell proliferation and migration. Int. J. Oncol. 50, 1671-1682 (2017).

164. Jiao, C. et al. IncRNA-UCA1 enhances cell proliferation through functioning as a ceRNA of Sox4 in esophageal cancer. Oncol. Rep. 36, 2960-2966 (2016).

165. Li, J. Y., Ma, X. \& Zhang, C. B. Overexpression of long non-coding RNA UCA1 predicts a poor prognosis in patients with esophageal squamous cell carcinoma. Int. J. Clin. Exp. Pathol. 7, 7938-7944 (2014).

166. Yu, X., Zheng, H., Chan, M. T. \& Wu, W. K. K. BANCR: a cancer-related long noncoding RNA. Am. J. Cancer Res. 7, 1779-1787 (2017).

167. Shi, Y. et al. Downregulated long noncoding RNA BANCR promotes the proliferation of colorectal cancer cells via downregualtion of p21 expression. PLOS ONE 10, e0122679 (2015).

168. Li, L., Zhang, L., Zhang, Y. \& Zhou, F. Increased expression of LncRNA BANCR is associated with clinical progression and poor prognosis in gastric cancer. Biomed. Pharmacother. 72, 109-112 (2015).

169. Yang, $X$. et al. Long non-coding RNA HNF1A-AS1 regulates proliferation and migration in oesophageal adenocarcinoma cells. Gut $\mathbf{6 3}, 881-890$ (2014).

170. Dang, Y. et al. Expression and clinical significance of long non-coding RNA HNF1A-AS1 in human gastric cancer. World J. Surg. Oncol. 13, 302 (2015). 